\title{
Pembuatan Antena Reflektor Parabola Lingkaran untuk Penerima Sinyal Televisi pada Jalur UHF
}

\author{
Parabolic Circle Reflector Antenna Making for \\ Television Signal Receiver on UHF Line
}

\author{
Nasrul \\ Jurusan Teknik Elektro Politeknik Negeri Padang Kampus Limau Manis Padang \\ Telp. 0751-72590 Fax. 0751-72576 Email: nasrulnawi@yahoo.com
}

\begin{abstract}
An antenna is a device that can receive electromagnetic waves at the receiver, and radiate electromagnetic waves on the transmitter. With the antenna we can receive information transmitted by the transmitting station through the receiver. In other words antenna helps in doing long distance connection with transmitter. In general, the antenna used to receive television signals uses many elements such as driven, reflectors, and directors. But in this study the antenna was made by using a parabolic reflector with a halflambda driven dipole without using a director.

Antenna is made there are several parameters measured as a proof of the success of the antenna. The parameters are: antenna gain, antenna impendance, VSWR (Voltage Standing Wave Ratio). The success of the antenna is also determined by the antenna's ability to receive a television signal which can also be seen by performing a direct test of the antenna.
\end{abstract}

Keywords: Parabolic, vswr, db

\section{PENDAHULUAN}

Pesatnya arus informasi di era globalisasi ini mendorong setiap orang untuk mendapatkan berita-berita dari seluruh belahan dunia secara cepat dan akurat. Salah satu media yang memenuhi kriteria tersebut adalah televisi, melalui siaran televisi masyarakat tidak saja dapat mendapatkan beragam informasi dan program berita lainnya namun juga memperoleh hiburan yang murah meriah yang langsung hadir ketengah-tengah keluarga.

Sebagaimana yang kita ketahui bahwa ditanah air kita dalam dekade terakhir ini, sudah banyak bermunjulan siaran televisi swasta disamping televisi pemerintah (TVRI), seperti yang dimaksud adalah stasiun televisi RCTI, SCTV, ANTV, TPI, INDOSIAR, METRO TV, TRANS TV, dan lainnya. Hal ini disebabkan stasiun-stasiun siaran televisi nasional tersebut memancar pada frekuensi-frekuensi yang berada pada jalur atau band VHF (30 MHz-300 MHZ) hingga UHF (300 MHz-3000 MHZ).
Dan salah satu alternatif yang dapat dikembangkan untuk penerimaan sinyal televise tersebut adalah dengan penggunaan antena reflektor parabolla lingkaran, antena reflektor parabolla lingkaran yang merupakan salah satu bentuk antena yang dipergunakan untuk jalur broadband karena pancarannya dipusatkan pada satu titik, maka penguatan antena ini sangat besar, dan dapat mencapai $50 \mathrm{~dB}$.

Berdasarkan latar belakang dapat diidentifikasi permasalahn pada penelitian ini yaitu:

1. Bagaimana merancang dan membuat suatu antena dengan dua band frekuensi yang dijadikan satu antena dapat dipergunakan untuk penerima sinyal televisi.

2. Bagaimana mengatasi inefisiensi dan ketidakpratisan pemekaian antena penerima sinyal televisi dengan dua band frekuensi yang memerlukan pemasangan dua buah antena yang terpisah

3. Bagaimana meningkatkan kemampuan instruktur dan mahasiswa dalam 
pratikum antena yang berorientasi objek dapat diwujudkan.

Dari permasalahan diatas penelitian ini yaitu berupa pembuatan antena yang cocok untuk menjawab permasalahan tersebut. Berdasarkan persyarat teknis yang sesuai dengan kondisi pemakai maka antena yang dipilih adalah antena reflektor parabolla lingkaran karena mempunyai penguatan (gain) $50 \mathrm{~dB}$.

Untuk menguji tingakat keberhasilan dari penelitian ini dapat dilihat beberapa indikatornya adalah:

1. Dengan adanya pembuatan antena penerima sinayal televisi pada band VHF dan UHF yang dijadikan satu antena penerima, ini sudah sesuai dengan tujuan yang dihadapi.

2. Mahasiswa mendapat tambahan materi pratikum antena yaitu dalam perancangan, pembuatan dan pengukuran antena pada frekuensi jalur lebar yang diterapkan pada antena penerima sinyal televisi pada frekuensi VHF (Very hight frekuensi) dan UHF (Ultra hight frekuensi).

3. Membuat tambahan referensi antena jalur lebar di labor telekomuniasi yang difokuskan pada antena penerima sinyal televisi.

\section{Pengertian Antena Parabolik}

Antena parabola merupakan antena yang menggunakan reflektor parabola, permukaan melengkung dengan bentuk penampang parabola, untuk mengarahkan gelombang radio. Bentuk yang paling umum adalah berbentuk seperti piring dan populer disebut antena parabolia atau parabolik. Keuntungan utama dari antena parabola bahwa memiliki directivity tinggi. Fungsinya mirip dengan reflektor sorot atau senter untuk mengarahkan gelombang radio dalam balok sempit, atau menerima gelombang radio dari satu arah tertentu saja. Antena parabola mempunyai beberapa keuntungan tertinggi, yaitu mereka dapat menghasilkan beamwidths sempit, dari setiap jenis antena. Dalam rangka mencapai beamwidths sempit, reflector parabola harus jauh lebih besar dari pada panjang gelombang radio yang digunakan, sehingga antena parabola yang digunakan di bagian frekuensi spectrum radio, di UHF dan (SHF) microwave frekuensi, dimana panjang gelombang yang cukup kecil bahwa reflector mudah berukuran dapat digunakan.

Antena parabola digunakan sebagai high gain antena untuk point-to-point komunikasi, dalam aplikasi seperti link estafet microwave yang membawa telepon dan sinyal televisi antara kota-kota terdekat, nirkabel WAN / LAN link untuk komunikasi data, komunikasi satelit dan antena pesawat ruang angkasa komunikasi. Antena parabola juga digunakan dalam teleskop radio. Penggunaan besar lainnya dari antena parabola adalah untuk antena radar, dimana ada kebutuhan untuk mengirimkan sinar sempit dari gelombang radio utnuk menemukan benda seperti kapal, pesawat terbang, dan peluru kendali. Dengan munculnya piring satelit televise rumah, antena parabola telah menjadi fitur umum dari lanskap Negara-negara modern.

\section{Feeder}

Feeder adalah bagian dari antena parabolik yang berfungsi untuk mengumpankan energi kepada reflektor untuk kemudian dipantulkan menuju kesuatu arah. Feeder ini akan diletakkan pada bagian sensitif reflektor atau biasa disebut titik fokus reflektor. Feeder terdiri dari tabung sensitive dan USB wireless adapter. Bahan yang digunakan untuk membuat tabung sensitif bisa dari banyak bahan, contohnya kaleng susu, pipa PVC dll. Didalam tabung sensitif inilah nantinya akan diletakkan USB wireless adapter.

\section{Reflektor}

Pada parabolik antena reflektor, feed (sumber pemancar primer) diletakkan pada titik fokus dan pancarannya diarahkan pada reflektor parabola, sehingga jika berkas sinyal mengenainya, berkas ini akan 
direfleksikan sesuai dengan hukum Snellius : Sudut datang = Sudut Pantul

Jadi berkas yang dipancarkan oleh feed akan mengenai suatu titik di reflektor, berkas ini akan direfleksikan sesuai dengan hukum refleksi ke posisi tertentu dengan nilai $\mathrm{x}$ yang sama dengan titik refleksi atau dengan kata lain berkas ini akan direfleksikan secara paralel, sehingga setelah berkas •berkas pancaran ini direfleksikan oleh reflector parabola didapatkan pancaran energi yang paralel atau didapatkan phasa gelombang yang datar.

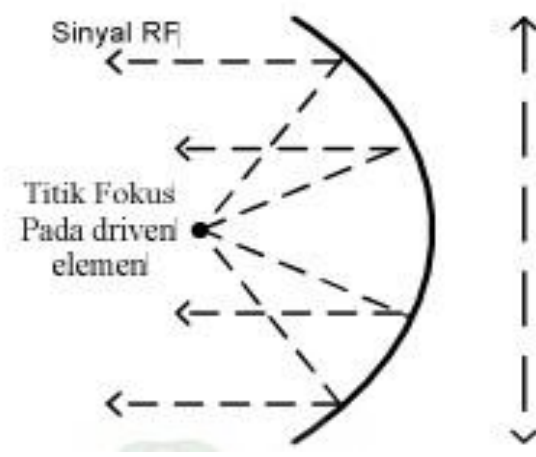

Gambar 1. Pantulan Sinyal pada Reflektor

Energi yang dipancarkan oleh feed primer dititik focus tanpa keberadaan reflektor parabola akan berdivergensi, terbagi kedalam ruang dengan bentuk phasa seperti bola. Tetapi dengan keberadaan reflektor, energi pancaran bisa lebih dikonsentrasikan menuju ke suatu arah. Karena berkas sinyal akan paralel dan tidak menyebar diruang.

\section{METODOLOGI}

Agar dicapainya sasaran seperti yang diharapkan, maka langkah-langkah atau metodologi yang dirtawarkan adalah sebagai berikut:

1. Studi literatur yang materinya berkaitan langsung dengan usulan kegiatan penelitian.

2. Melakukan diskusi dengan rekan satu tim penelitian untuk mencari solusi yang lebih efesien.

3. Metoda pendekatan antara teori dan praktek dengan mengadakan proses perhitungan-perhitungan

(merencanakan) parameter teknis dan fisik dari antena beserta balun yang digunakan.

4. Aktifitas di bengkel mekanik berupa implementasi hasil perhitungan pada langkah (3) di atas ke dalam bentuk fisik antena yaitu sistem antena televisi dengan reflektor parabolla.

5. Melakukan uji coba keandalan sistem di laboratorium, bila terdapat kekurangan atau penyimpangan dari parameter teknis yang telah diperkirakan sebelumnya, maka akan dilakukan evaluasi ulang hingga didapatkan hasil yang sesuai dengan pedoman berupa parameter yang telah dibuat sebelumnya.

6. Melakukan uji coba pembanding yaitu berupa pemakaian jenis antena VHF dan UHF yang sudah banyak di pasaran dan dapat diambil kesimpulan dalam penelitian ini.

\section{HASIL}

\section{Perancangan Antena}

Dalam pembuatan antena yang diharapkan mendapatkan hasil yang maksimal seperti yang kita inginkan perlu dilakukan sebuah perencanaan sebelum melakukan pekerjaan. Dengan menggunakan langkah-langkah yang telah diatur dalam perencanaan, diharapkan terciptanya suatu hasil yang baik dan dapat bekerja seperti yang kita inginkan.

Berdasarkan teori-teori yang didapat dari beberapa literatur, maka dilakukan perencanaan antena yang kemudian dilanjutkan dengan pembuatan antena. adalah:

Tujuan dari pelaksanaan yang dibuat

a. Mengaplikasikan teori-teori yang didapat berdasarkan literatur yang dilakukan yang berhubungan langsung dengan antena.

b. Untuk menghindari terjadinya kesalahan dan pemborosan terhadapa antena yang dibuat. 
c. Membuat antena yang sesuai dengan frekuensi kerja yang dibutuhkan dalam aplikasinya.

d. Untuk mendapatkan sebuah antena dengan hasil yang lebih baik dan dapat digunakan semaksimal mungkin.

Perencanaan waktu yang dilakukan disini adalah perencanaan waktu terhadap pembuatan antena mulai dari awal sampai alat selesai dibuat. Perencanaan waktu yang dibuat adalah sebagai berikut :

1. Studi literatur

2. Mendisain bentuk dan ukuran dari antena yang akan dibuat

3. Survey bahan dan alat yang diperlukan dipasaran

4. Pembuatan antena

5. Pengujian antena

6. Pengukuran dan penganbilan data

7. Penulisan laporan

Tujuan dari perencanaan antena adalah untuk mendapatkan penerimaan daya yang maksimum oleh antena, yang diharapkan mendapatkan nilai dari VSWR ( Voltage Standing Wave Ratio ) mendapatkan nilai satu atau sekecil mungkin.

Secara teorinya dapat diketahui halhal yang perlu diperhatikan dalam pembuatan antena adalah sebagai berikut :

a. Hubungan elemen-elemen antena dengan frekuensi kerja yang akan digunakan.

b. Hubungan antara ukuran elemen reflektor parabola dengan gain yang diharapkan.

c. Impendansi antena dan saluran transmisi yang digunakan.

\section{Perencanaan ukuran elemen driven antena}

Pada pembuatan antena ini menggukan frekuensi UHF yang diawali pada kanal 39 ( $620 \mathrm{MHz}-626 \mathrm{MHz}$ ) sampai pada kanal 49 ( $680 \mathrm{MHz}-686$ $\mathrm{MHz}$ ). Dari frekuensi yang telah diketahui dapat dicari ukuran dari driven yang digunakan dengan cara sebagai berikut :

$$
\underline{620 \mathrm{MHz}+686 \mathrm{MHz}}=653 \mathrm{MHz}
$$

2

Panjang gelombang $(\lambda)$ dari frekuensi tengah tersebut adalah :

$$
\begin{aligned}
& \lambda=\mathrm{C} / \mathrm{f} \\
& =\left(3.10^{8} \mathrm{~m} / \mathrm{det}\right) /\left(653.10^{6}\right. \\
& \mathrm{MHz}) \\
& =0,4594 \text { Meter. }
\end{aligned}
$$

Karena driven yang digunakan adalah dipole $1 / 2$ lambda $(1 / 2 \lambda)$ maka panjang driven yang digunakan adalah :

$$
\begin{aligned}
0,5 \lambda & =0,5.0,4594 \text { meter } \\
& =0,2297 \text { meter }
\end{aligned}
$$

\section{Diameter Reflektor Parabola}

Karena gain yang diharapkan adalah $10 \mathrm{~dB}$, maka dapat ditentukan ukuran reflektor yang harus digunakan adalah : $\mathrm{G}=20 \log \mathrm{d}_{(\mathrm{m})}+20 \log \mathrm{f}_{(\mathrm{GHz})}+17,8$ (simetrik)

$10 \mathrm{~dB}=20 \log \mathrm{d}_{(\mathrm{m})}+20 \log 0,653_{(\mathrm{GHz})}+$ 17,8

$10 \mathrm{~dB}=20 \log \mathrm{d}_{(\mathrm{m})}-3,702+17,8$

$10 \mathrm{~dB}=20 \log \mathrm{d}_{(\mathrm{m})}+14,098$

$20 \log \mathrm{d}_{(\mathrm{m})}=10-14,098$

$20 \log \mathrm{d}_{(\mathrm{m})}=-4,098$

$\log \mathrm{d}_{(\mathrm{m})}=0,2049$

$\mathrm{d}=\operatorname{arc} \log (-0,2049)$

$\mathrm{d}=0,623$ meter

$\mathrm{d}=0,6$ meter

Selain menggunakan perhitungan seperti diatas dapat juga dilakukan dengan menggunakan rumus sebagai berikut :

$$
\begin{aligned}
\mathrm{G} & =\frac{4 \pi \mathrm{A}}{\lambda^{2}} \\
\mathrm{~A} & =\eta \pi(\mathrm{d} / 2)^{2 \cdots \cdots} \quad\left(\begin{array}{l}
\eta=0,6 \text { sampai } \\
0,8)
\end{array}\right. \\
\mathrm{A} & =0,6 \cdot \pi(\mathrm{d} / 2)^{2} \\
& =1,885\left(\mathrm{~d}^{2} / 4\right) \\
& =0,47125 \mathrm{~d}^{2}
\end{aligned}
$$

Maka:

$$
\begin{aligned}
& \mathrm{G}=\frac{4 \pi \mathrm{A}}{\lambda^{2}} \\
\mathrm{G}_{(\mathrm{dB})} & =10 \log 4 \pi \mathrm{A} /\left(\lambda^{2}\right) \\
& =10 \log \frac{4 \pi \cdot 0,47125 \mathrm{~d}^{2}}{\lambda^{2}} \\
& =10 \log \frac{4 \pi \cdot 0,47125 \mathrm{~d}^{2}}{0,4594^{2}} \\
10 & =\frac{5,9219 \mathrm{~d}^{2}}{0,21104}
\end{aligned}
$$




$$
\begin{aligned}
& 10=28,0605 \underline{\mathrm{d}^{2}} \\
& \mathrm{~d}^{2}=10 / 28,0605 \\
& \mathrm{~d}=0,5969 \text { meter. } \\
& \mathrm{d}=0,6 \text { meter }
\end{aligned}
$$

Untuk menentukan titik fokus dari reflektor parabola yang dibuat atau untuk menentukan jarak antara driven dengan reflektor yang digunakan digunakan rumus sebagai berukut :

$$
\begin{aligned}
& \mathrm{F}=\mathrm{Y}^{2} / 4 \mathrm{X} \\
& \mathrm{F}=30^{2} / 4.18,5 \\
& \mathrm{~F}=12,16 \mathrm{~cm}
\end{aligned}
$$

\section{Hasil Pelaksanaan Kegiatan}

Untuk lebih jelasnya kontruksi antena parabola dapat dilihat pada gambar berikut:

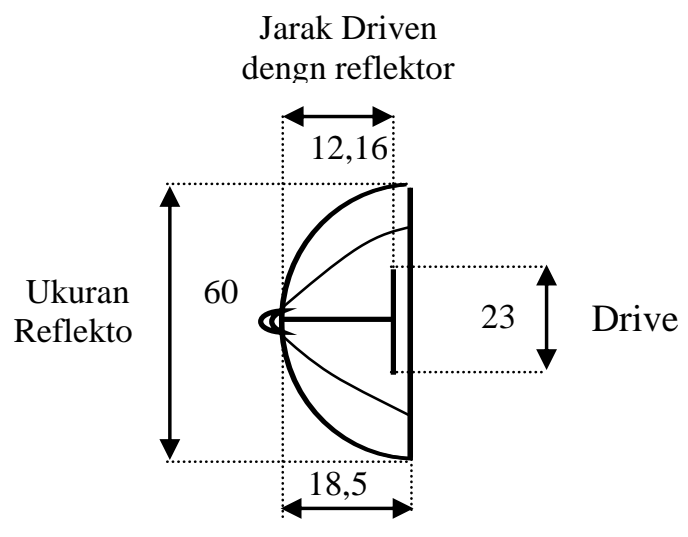

Kedalaman

Gambar 2. Kontruksi antena parabola secara

Dalam pembuatan antena membutuhkan bahan-bahan sebagai berikut

a. Jaring alumunium digunakan untuk permukaan reflektor parabola

b. Alumunium siku digunakan untuk pembuatan kerangka lingkaran reflektor parabola.

c. Alumunium plat dengan lebar $1 \mathrm{~cm}$ yang digunakan untuk kerangka kelengkungan parabola.

d. Pipa alimunium diameter $2 \mathrm{~cm}$ yang digunakan untuk batang pegangan driven

e. Pipa alumunium $0,8 \mathrm{~cm}$ digunakan untuk driven $1 / 2$ lambda f. Bahan osilator berupa plastik untuk driven

g. Kabel koaksial untuk saluran transmisi

h. Konektor, baut, mur dan paku klem.

Dengan menggunakan bahan-bahan diatas maka dibuatlah antena yang sesuai dengan ukuran-ukuran yang telah dibuat dalam perencanaan diatas. Seteleh antena dibuat antena akan diukur, bukti dari keberhasilan antena dapat ditentukan dari hasil pengukuran yang dilakukan dan dapat menerima siaran televisi secara baik dan bersih.

\section{PEMBAHASAN}

\section{Diskripsi Kerja}

Selain ditentukan oleh kemampuan antena untuk bekerja sebagaimana mestinya, keberhasilan dalam melakukan pembuatan antena juga dinyatakan dengan hasil pengukuran terhadap parameterparameter yang dapat diukur pada alat tersebut. Jika alat yang dihasilkan dapat bekerja dengan baik tentu akan diikuti dengan hasil pengukuran yang sesuai dengan perhitungan menggunakan teoriteori yang ada.

Pengukuran merupakan suatu tahap yang sangat menentukan tingkat keberhasilan pembuatan alat dimana hasil pengukuran ini akan memperkuat argumentasi terhadap kemampuan suatu alat yang telah dibuat.

\section{Pengujian Antena}

\section{Pengujian Voltage Standing Wave Ratio (VSWR)}

Pengujian Voltage Standing Wave Ratio (VSWR) dimaksudkan untuk mengetahui ketidaksesuaian antara beban dengan saluran transmisi pada antena. Pengukuran VSWR biasanya didahului dengan mengukur koefisien refleksi (pantul). Koefisien pantul adalah perbandingan sinyal yang dipantulkan terhadap sinyal datang. Setelah didapat data koefisien pantul (disimbolkan dengan $|\Gamma|$ ) maka dengan data tersebut dapat dihitung harga VSWR. 
Pada pengukuran ini digunakan sebuah alat yang disebut RF Impedance Analyzer hp 4191 A, dan blok diagramnya dapat dilihat sebagai berikut :

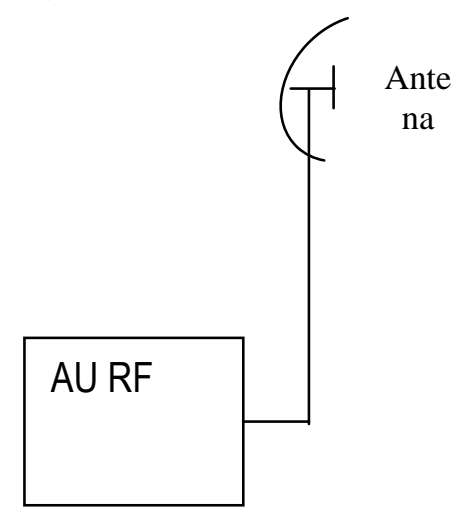

Gambar 3. Blok diagram pengukuran VSWR dan Koefisien Refleksi

Adapun peralatan yang digunakan dalam pengukuran VSWR ini adalah :

1. RF Impedansi Analizer hp 4191A

2. Kabel sependek mungkin

3. Konektor

4. Antena yang akan diukur yaitu Antena Reflektor Parabola

Hasil pengukuran yang dilakukan dicatat hasilnya pada tabel dibawah ini. Tabel 1. Data hasil pengukuran koefisien refleksi $(|\Gamma|)$

\begin{tabular}{|c|c|}
\hline $\begin{array}{c}\text { Frekuensi } \\
(\mathbf{M h z})\end{array}$ & $|\boldsymbol{\Gamma}|$ \\
\hline 620 & 0,5 \\
\hline 623 & 0,44 \\
\hline 626 & 0,47 \\
\hline 644 & 0,47 \\
\hline 647 & 0,43 \\
\hline 650 & 0,34 \\
\hline 668 & 0,16 \\
\hline 671 & 0,14 \\
\hline 674 & 0,14 \\
\hline 680 & 0,15 \\
\hline 683 & 0,15 \\
\hline 686 & 0,14 \\
\hline
\end{tabular}

Kemudian dihitung VSWR dari datadata di atas dengan menggunakan rumus :

$$
\operatorname{VSWR}=\frac{1+|\Gamma|}{1-|\Gamma|}
$$

Didapatkan hasil sebagai berikut :

Tabel 2. Data VSWR Antena

\begin{tabular}{|c|c|}
\hline $\begin{array}{c}\text { Frekuensi } \\
(\mathbf{M h z})\end{array}$ & VSWR \\
\hline 620 & 3 \\
\hline 623 & 2,57 \\
\hline 626 & 2,77 \\
\hline 644 & 2,77 \\
\hline 647 & 2,5 \\
\hline 650 & 2 \\
\hline 668 & 1,38 \\
\hline 671 & 1,32 \\
\hline 674 & 1,32 \\
\hline 680 & 1,35 \\
\hline 683 & 1,35 \\
\hline 686 & 1,32 \\
\hline
\end{tabular}

\section{Pengukuran Impedansi}

Karakteristik impedansi yang ada pada antena, saluran transmisi dan input pesawat televisi haruslah sama satu sama lain. Karena adanya hal yang demikian ini setidaknya saluran transmisi akan mampu menyalurkan energi secara maksimum. Keselarasan impedansi memang sangat diperlukan. Sebab bila sampai terjadi apa yang dinamakan "mismatch impedance" (ketidaksesuaian impedansi) akan menyebabkan tayangan gambar TV menjadi tidakk sepenuhnya sempurna, atau dengan kata lain mutu gambar menjadi buruk.

Impedansi dari sebuah antena erat kaitannya dengan nilai VSWR antena tersebut. Sebagaimana halnya pada pengukuran koefisien refleksi untuk menentukan koefisien pantul dan VSWR sebuah antena, pengukuran impedansi ini juga dilakukan dengan menggunakan peralatan yang sama dengan pengukuran VSWR antena. Begitu juga dengan diagram pengukurannya sama dengan diagram pengukuran koefisien pantul dan VSWR.

Prosedur pengukuran impedansi antena adalah sebagai berikut :

1. Mengkalibrasi peralatan Impedansi Analyzer. 
2. Mengusun peralatan seperti blok diagram sama seperti pengukuran koefisien refleksi dan VSWR.

3. Mengeset Impedansi Analyzer pada posisi $|z|$.

4. Melakukan pengukuran pada frekuensi yang telah ditentukan.

5. Mencatat data hasil pengukuran pada tabel untuk masing-masing frekuensi.

Dari pengukuran yang dilakukan didapatkan data-data nilai impedansi sebagai berikut :

Tabel 3 Data hasil pengukuran impedansi antena

\begin{tabular}{|c|c|}
\hline $\begin{array}{c}\text { Frekuensi } \\
(\mathbf{M h z})\end{array}$ & $\begin{array}{c}\text { Impedansi I } \\
\mathbf{z} \text { I }\end{array}$ \\
\hline 620 & 80,5 \\
\hline 623 & 73,17 \\
\hline 626 & 66,66 \\
\hline 644 & 65,42 \\
\hline 647 & 59,65 \\
\hline 650 & 60,23 \\
\hline 668 & 50,30 \\
\hline 671 & 50,60 \\
\hline 674 & 50,53 \\
\hline 680 & 40,66 \\
\hline 683 & 40,66 \\
\hline 686 & 39,96 \\
\hline
\end{tabular}

\section{Pengukuran Penguatan (Gain)}

Untuk pengukuran gain atau penguatan daya yang dihasilkan oleh antena dengan reflektor parabola ini, maka sebelumnya dilakukanlah pengukuran penerimaan daya pada antena referensi yang berbentuk antena dipole $1 / 2 \lambda$, sebagai pembanding bagi daya yang diterima oleh antena yang akan diukur penguatannya. Jadi dalam hal ini pengukuran gain yang sebenarnya adalah membandingkan penguatan antena yang diukur (under test antena) dengan penguatan antena standar.

Pengukuran ini menggunakan peralatan-peralatan sebagai berikut :

1. Signal Generator hp 8656B sebagai pemancar.

2. Antena dipole $1 / 2 \lambda$ sebagai antena pemancar dan antena referensi.
3. Antena dengan reflektor parabola sebagai antena yang akan diukur penguatannya.

4. Spektrum Analyzer GSP-810 sebagai penerima.

5. Kabel penghubung $75 \Omega$.

6. Kabel koaksial

7. Konektor

Blok diagram dari pengukuran ini adalah :

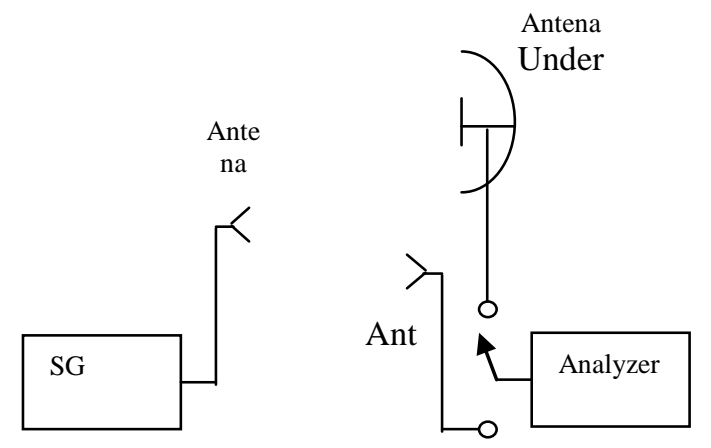

Gambar 4. Blok diagram

Pengukuran dilakukan pada empat kanal frekuensi, yaitu kanal 39 UHF, 43 UHF, 47 UHF dan 49 UHF. Frekuensi pada kanal 39 UHF adalah : 620, 623 dan 626 $\mathrm{MHz}$; frekuensi pada kanal 43 UHF adalah 644, 647, dan $650 \mathrm{MHz}$; frekuensi pada kanal 47 UHF adalah 668, 671 dan 674 $\mathrm{MHz}$; dan frekuensi pada kanal 49 UHF adalah 680, 683 dan $686 \mathrm{MHz}$.

Data dari hasil pengukuran penerimaan daya pada antena referensi dan antena under test dapat dilihat pada tabel berikut.

Tabel 4. Data hasil pengukuran gain antena

\begin{tabular}{|c|c|c|c|c|}
\hline $\begin{array}{c}\text { Frekue } \\
\text { nsi } \\
(\mathrm{MHz})\end{array}$ & $\begin{array}{c}\mathrm{PR}_{\mathrm{x}} \text { refer } \\
\text { ensi } \\
(\mathrm{dBm})\end{array}$ & $\begin{array}{c}\mathrm{PR}_{\mathrm{x}} \mathrm{un} \\
\text { der } \\
\text { test } \\
(\mathrm{dBm})\end{array}$ & $\begin{array}{l}\mathrm{Ga} \\
\text { in } \\
\text { (d } \\
\mathrm{B})\end{array}$ & $\begin{array}{c}\text { Gain } \\
(\mathrm{m} \\
\mathrm{W})\end{array}$ \\
\hline 620 & -64 & -54 & 10 & 6,3 \\
\hline 623 & -68 & -56 & 12 & $\begin{array}{c}15,8 \\
5\end{array}$ \\
\hline 626 & -67 & -55 & 12 & $\begin{array}{c}15,8 \\
5\end{array}$ \\
\hline 644 & -66 & -56 & 10 & 10 \\
\hline 647 & -68 & -58 & 10 & 10 \\
\hline 650 & -67 & -58 & 9 & 7,94 \\
\hline 668 & -65 & -52 & 13 & $\begin{array}{c}19,9 \\
5\end{array}$ \\
\hline
\end{tabular}




\begin{tabular}{|c|c|c|c|c|}
\hline 671 & -75 & -54 & 21 & $\begin{array}{c}125, \\
89\end{array}$ \\
\hline 674 & -72 & -54 & 18 & $\begin{array}{c}63,0 \\
9\end{array}$ \\
\hline 680 & -68 & -56 & 12 & $\begin{array}{c}15,8 \\
5\end{array}$ \\
\hline 683 & -68 & -57 & 11 & $\begin{array}{c}12,5 \\
9\end{array}$ \\
\hline 686 & -66 & -57 & 9 & 7,94 \\
\hline
\end{tabular}

\section{Pengukuran Pola Radiasi}

Pengukuran pola radiasi bertujuan untuk mengetahui sifat pancaran gelombang elektromagnetik dari sebuah antena. Pada pengukuran ini antena difungsikan sebagai antena penerima, sedangkan sebagai pemancar digunakan antena referensi dipole $1 \lambda$. Biasanya antena referensi adalah dipole $1 / 2 \lambda$ tapi disini digunakan referensi dipole $1 \lambda$ karena antena inilah yang tersedia. Disini pengukuran pola radiasi antena penerima (antena reflektor parabola) dilakukan pada jarak 7 meter dari antena pemancar dengan melakukannya pada dua posisi pemasangan antena yaitu pemasangan antena secara horizontal dan pemasangan antena secara vertikal.

Pengukuran pola radiasi dilakukan pada tiap-tiap frekuensi tengah dari kanal UHF yang dipakai, yaitu kanal 39, 43, 47 dan kanal 49. Frekuensi tengah itu adalah $623 \mathrm{MHz}, 647 \mathrm{MHz}, 671 \mathrm{MHz}$ dan 680 $\mathrm{MHz}$.

Adapun peralatan yang digunakan pada pengukuran ini adalah :

1. Antena dipole $1 / 2 \lambda$ sebagai pemancar

2. Antena Under Test (antena dengan reflektor

3. parabola)

4. Antena Rotator

5. Signal Generator hp 8656B

6. Spektrum Analyzer GSP-810

7. Kabel Penghubung $75 \Omega$

8. Kabel koaksial

9. Konektor
Bentuk blok diagram pengukuran antena
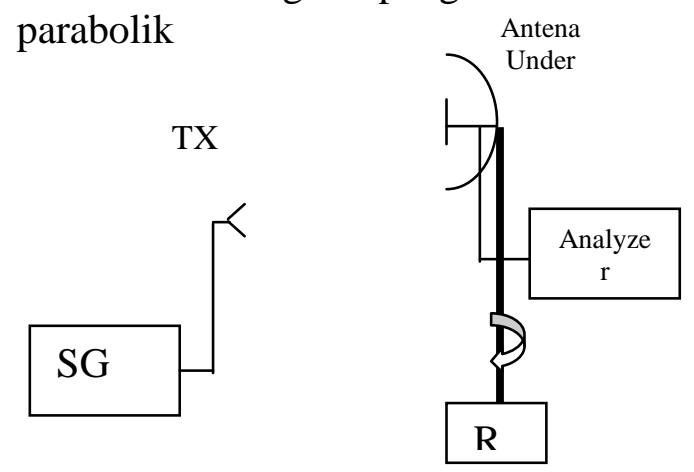

Gambar 5. Blok diagram

Bentuk pola radiasi berdasarkan data yang didapat adalah :

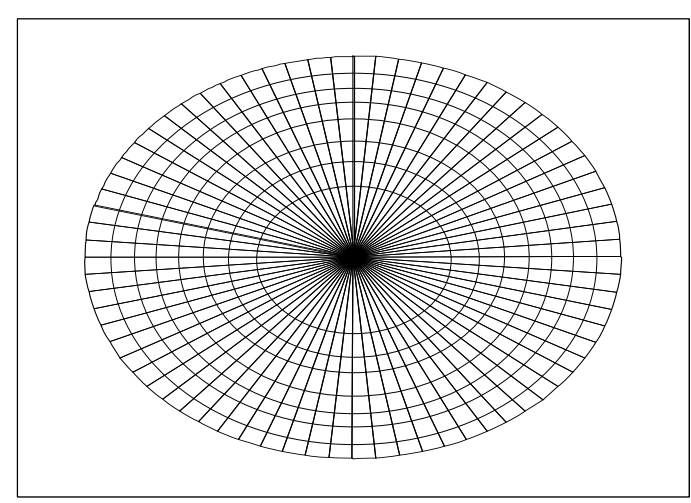

Gambar 6. Pola Radiasi

\section{SIMPULAN}

Antena penerima televisi dengan reflektor parabola ini digunakan untuk menerima sinyal-sinyal televisi pada jalur UHF kanal 39, 43, 47 dan 49.

2. Bahan yang digunakan untuk pembuatan antena adalah alumunium karena bahan ini lebih ringan dari logam lainnya dan juga tahan terhadap korosi (karat) yang diakibatkan oleh perubahan cuaca.

3. Dengan menggunakan antena reflektor parabola didapatkan penguatan antena sebesar $9 \mathrm{~dB}$ sampai $21 \mathrm{~dB}$, di ukur pada frekuensi $620 \mathrm{MHz}$ sampai $686 \mathrm{MHz}$.

4. Pola radiasi yang baik untuk penerimaan sinyal yang maksimum dari antena reflektor parabola ini adalah polarisasi horizontal. 
5. Nilai Voltage Standing Wave Ratio dari antena reflektor parabola yang dibuat adalah berkisar antara 1,33 sampai 3 .

\section{SARAN}

Jika antena di aplikasikan sebagai penerima televisi sebaiknya dipasang pada posisi garis lurus dan tanpa penghalang (Line of Sight $=$ LOS $)$ terhadap antena pemancar sehingga mendapatkan penerimaan yang lebih maksimu

\section{DAFTAR PUSTAKA}

Constantine A. Balanis, Antena Theory : Analysis and Design, John And Sons, Inc, New York, 1982.

Gerald J. Hall, The ARRL Antenna Book, 16 th Edition, The American Radio Relay League, Newington, 1991.

Herbert S, Brier, VHF Hnadbook, $2^{\text {nd }}$ Edition. Radio Publication, Inc, Wilton, Conn. USA, 1979

John D. Kraus, Antennas McGraw-Hill, Inc, New York, 1988.

Kraus, Antenas, $2^{\text {nt }}$ Edition, Mc. Graw Hill Book Co, Singapore, 1988.

Nasrul, Pembuatan Antena Heliks Yang Dapat Dipergunakan Untuk Penerimaan Sinyal Televisi Pada Jalur VHF dan UHF, Laporan Penelitian Dana Rutin Politeknik Negeri Padang, tahun 1999/2000.

R. Harold Kinley. CET, Standar Radio Communication Manual : With Instrumention and Testing Tecniques, Prentice-Hall, Inc New Jersey, 1985

Richard J. Jhonson and Henry Jasik, Antena Engineering Hand Book, $2^{\text {nd }}$ Edition, Mc Grow Hill, Inc New York, 1984.
Robert G. Brown, Robert A Sharpe, William L, Hughes, and Robert E. Post. Line Wave and Antennas : The Transmission of Electric Energy, $2^{\text {nd }}$, Edition, John Willey ans Sons, Inc, New York. 1973

Warren L. Stutzman and Gary A. Thiele, Antenna Theory and Design, John Willey and Sons, Inc, New York, 1981.

Yulindon, Pembuatan Antena Log Priodic Dipole Array (LPDA) Yang Dapat Dipergunakan Untuk Penerimaan Sinyal Televisi Pada Jalur VHF dan UHF, Laporan Penelitian P5D, Dirjen Dikti, Depdikbud Kontrak Nomor $\quad$ 005/B/SPP/P4/VIII/98 tanggal 1 Agustus 1998 